\title{
Eddy correlation measurements of oxygen fluxes in permeable sediments exposed to varying current flow and light
}

\author{
Peter Berg, ${ }^{1,}{ }^{*}$ Matthew H. Long, ${ }^{1}$ Markus Huettel, ${ }^{2}$ Jennie E. Rheuban, ${ }^{1}$ Karen J. McGlathery, ${ }^{1}$ \\ Robert W. Howarth, ${ }^{3}$ Kenneth H. Foreman, ${ }^{4}$ Anne E. Giblin, ${ }^{4}$ and Roxanne Marino ${ }^{3}$
}

${ }^{1}$ Department of Environmental Sciences, University of Virginia, Charlottesville, Virginia

${ }^{2}$ Department of Earth, Ocean and Atmospheric Science, Florida State University, Tallahassee, Florida

${ }^{3}$ Department of Ecology and Evolutionary Biology, Cornell University, Ithaca, New York

${ }^{4}$ The Ecosystems Center, Marine Biological Laboratory, Woods Hole, Massachusetts

\begin{abstract}
Based on noninvasive eddy correlation measurements at a marine and a freshwater site, this study documents the control that current flow and light have on sediment-water oxygen fluxes in permeable sediments. The marine sediment was exposed to tidal-driven current and light, and the oxygen flux varied from night to day between -29 and $78 \mathrm{mmol} \mathrm{m}^{-2} \mathrm{~d}^{-1}$. A fitting model, assuming a linear increase in oxygen respiration with current flow, and a photosynthesis-irradiance curve for light-controlled production reproduced measured fluxes well $\left(R^{2}=0.992\right)$ and revealed a 4-fold increase in oxygen uptake when current velocity increased from $\sim 0$ to $20 \mathrm{~cm} \mathrm{~s}$. Application of the model to a week-long measured record of current velocity and light showed that net ecosystem metabolism varied substantially among days, between -27 and $31 \mathrm{mmol} \mathrm{m}^{-2} \mathrm{~d}^{-1}$, due to variations in light and current flow. This variation is likely typical of many shallow-water systems and highlights the need for long-term flux integrations to determine system metabolism accurately. At the freshwater river site, the sediment-water oxygen flux ranged from -360 to $137 \mathrm{mmol} \mathrm{m}^{-2} \mathrm{~d}^{-1}$. A direct comparison during nighttime with concurrent benthic chamber incubations revealed a 4.1 times larger eddy flux than that obtained with chambers. The current velocity during this comparison was $31 \mathrm{~cm} \mathrm{~s}^{-1}$, and the large discrepancy was likely caused by poor imitation by the chambers of the natural pore-water flushing at this high current velocity. These results emphasize the need for more noninvasive oxygen flux measurements in permeable sediments to accurately assess their role in local and global carbon budgets.
\end{abstract}

The oxygen flux between sediments with their biotic communities and the overlying water is the most commonly used proxy for benthic carbon mineralization and primary production (Canfield et al. 1993; Glud 2008). As a result, benthic oxygen exchange is a key component in carbon budgets on both local and global scales. The continental shelf contributes about $50 \%$ of benthic carbon mineralization in the ocean, and the highest rates are found near shorelines, where shallow water depths and nutrient and organic input from land boost primary production (Middelburg and Soetaert 2004; Middelburg et al. 2005). As a result, a quantitative understanding of carbon transformations on the inner shelf - an environment dominated by permeable sands (Emery 1968) - is essential for carbon cycle assessments. A similar argument can be made for freshwater systems that have recently been recognized as transforming or storing more than $50 \%$ of the carbon inputs from land rather than serving as passive conduits to the ocean (Cole et al. 2007; Aufdenkampe et al. 2011). Thus, numerous rivers and creeks lined with highly permeable sands likely play an important role in carbon cycling.

Despite the large number of studies that have focused on transport and biogeochemical processes in permeable sediments (Huettel and Webster 2000), there is less known about biogeochemical cycling in these sediments relative to muddy cohesive sediments. One reason for this discrepancy

\footnotetext{
*Corresponding author: pb8n@virginia.edu
}

is that it is more challenging to quantify processes in sands under realistic in situ conditions. Permeable sediments allow substantial advective transport of water that carries both dissolved and solid substances into and out of the open pore space between the sand grains (Huettel et al. 1996). This gives rise to a very different reaction scheme for biogeochemical processes-processes to which benthic fluxes are tightly linked - compared to what is typically found in muddy sediments. For example, the filtering of particulate organic matter by sands when flushed with bottom water and the transport of dissolved organic matter effectively transport 'food' for mineralization processes deep into the sands. This supply of organic matter, combined with the advective transport of oxygen into sands, stimulates oxic mineralization (Reimers et al. 2004; Cook et al. 2007). It is this flushing of sands and their exchange of water-bound constituents with the water column that are difficult to capture in benthic flux measurements.

The main drivers of advective transport in permeable sediments are well known. Pressure differences arising from current flows (Thibodeaux and Boyle 1987) and wave action (Riedl et al. 1972) over rippled or otherwise uneven sand surfaces can induce significant pore-water flow in the upper sand layers. Also, pumping activity of tube-building macrofauna can result in pore-water movement in permeable sands (Foster-Smith 1978). However, only a few studies have reported exchange and flow rates and their effects on biogeochemical cycling. Precht and Huettel 
(2003) estimated wave-driven exchange between sand and the water column in a wave tank that exceeded $500 \mathrm{~L} \mathrm{~m}^{-2} \mathrm{~d}^{-1}$. Reimers et al. (2004) also documented from lab experiments a many-fold increase in oxygen respiration in permeable sediments when they were flushed with pore water and hypothesized that in situ oxygen respiration must be highly variable and dependent on current and wave conditions. Similar findings were later reported by de Beer et al. (2005) and Cook et al. (2007). However, in situ pore-water exchange and flow rates and, in particular, their effect on biogeochemical cycling are still poorly quantified.

The most common way to measure benthic oxygen fluxes is by using in situ chambers. Traditional chamber incubations determine oxygen fluxes for a small, enclosed sediment area (typically $<0.25 \mathrm{~m}^{2}$ ) from concentration changes measured in the enclosed water through relatively long time periods (hours to days; Wild et al. 2004; Tengberg et al. 2005). This is an intrusive method that excludes natural flow and exchange of water-bound constituents and can bias flux measurements significantly for permeable sands (Cook et al. 2007; Berg and Huettel 2008; Glud 2008). Given the important role that permeable sediments play in carbon budgets on both local and global scales, this bias can have serious consequences for our understanding and assessment of benthic carbon flows and transformations.

In this study, we used the eddy correlation technique to measure oxygen fluxes (Berg et al. 2003) between permeable sands and the overlying water column. While the technique is more expensive and also technically more challenging to apply than traditional flux methods, it has unique advantages, especially for permeable sediments. For example, if the current direction is known, eddy correlation measurements can be obtained without disturbing the natural light and flow conditions and thus can incorporate in situ effects of pore-water flushing. Further, because the footprint (the sediment surface area that contributes to the flux) covers a relatively large area (typically $10-100 \mathrm{~m}^{2}$; Berg et al. 2007), it integrates spatial heterogeneities found in most benthic systems (Fenchel and Glud 2000; Wenzhofer and Glud 2004; Thouzeau et al. 2007). These characteristics clearly distinguish the eddy correlation technique and allow us to quantify and study oxygen fluxes in permeable sediments under natural field conditions - a task that is not possible with other flux approaches.

This study had two goals. The primary goal was to examine rates and controls of benthic oxygen fluxes for shallow-water permeable sediments using eddy correlation measurements under field conditions that included naturally varying light and current flow. To isolate the effects of the latter, we excluded wave motions from the study. The secondary goal was to examine and compare benthic oxygen fluxes measured in permeable sediments concurrently with the eddy correlation technique and in situ chambers. Two shallow-water sites with permeable sediment were used in the study, a site in a relatively well protected sandy marine embayment with tidal-driven varying current and a river site with a sandy bottom and a unidirectional current.

\section{Methods}

Site description-The marine site was located at the mouth of West Falmouth Harbor $\left(41.6067^{\circ} \mathrm{N}-70.6501^{\circ} \mathrm{W}\right)$, a small $\left(0.7 \mathrm{~km}^{2}\right)$ protected estuary on Cape Cod, Massachusetts, $8 \mathrm{~km}$ north of Woods Hole. Water depth in the estuary averages $2 \mathrm{~m}$, and its opening to the ocean is narrow $(80 \mathrm{~m})$. Due to the tidal-driven variation in water depth of 1-2 $\mathrm{m}$, there is a variable but predictable current flow that typically ranges from 0 to $20 \mathrm{~cm} \mathrm{~s}^{-1}$ inside the mouth of the estuary. As a result of this current, a distinct sandbar has formed here that stretches approximately $200 \mathrm{~m}$ along the main current direction. The permeability of the sand was $1.8 \times 10^{-11} \pm 0.11 \times 10^{-11} \mathrm{~m}^{2}$ (standard error [SE], $n=3$; measured as described by Klute and Dirksen 1986) and classified as "well-sorted sand or sand and gravel" according to Bear (1972). This permeability allows substantial pore-water flow and advective exchange with the overlying water column (Huettel and Gust 1992b). The sand was inhabited by microalgae, as evidenced by sporadic formations of small oxygen bubbles observed at the sand surface on sunny summer days under low-flow conditions. Much of the remaining estuary has muddy sediments, and dense seagrass beds (Zostera marina) are found in some areas. Salinity generally exceeds 28, and water residence time is short, on average $1-2 \mathrm{~d}$ for all of West Falmouth Harbor, which limits phytoplankton accumulation (Swaney et al. 2008). Eddy correlation data were collected at the center of the sandbar during day and night in the early spring of 2007 and the summers of 2007 , 2008 , and 2009. The size of the sandbar, relative to the sediment surface area that produces the eddy flux (Berg et al. 2007), was large enough to ensure that the measured exchange represented only the well-sorted sand. A few deployments measured during windy conditions showed small wind-generated wave motions. These were excluded from the flux analysis to isolate the effects of current flow on the oxygen exchange. Hereafter, this site is referred to as West Falmouth Harbor.

The freshwater site was located in the spring-fed Wakulla River $\left(30.2138^{\circ} \mathrm{N}-84.2618^{\circ} \mathrm{W}\right)$, a few kilometers south of Tallahassee, Florida. The site is characterized by a relatively constant current flow with an average of around $25 \mathrm{~cm} \mathrm{~s}^{-1}$. The water depth was $\sim 3 \mathrm{~m}$, and the sediment, consisting of a mixture of sand and gravel, had an average permeability of $2.3 \times 10^{-10} \pm 3.8 \times 10^{-11} \mathrm{~m}^{2}(\mathrm{SE}, n=3$; measured as described by Klute and Dirksen 1986). The river bottom was inhabited by microalgae, and some sparse vascular aquatic plants were present in the area where our instruments were deployed. Data were collected during a $2 \mathrm{~d}$ period in May 2008 in parallel deployments of two eddy correlation systems and five in situ chambers. The data include both daytime and nighttime measurements. Hereafter, this site is referred to as Wakulla River.

Eddy correlation measurements - Eddy correlation data were recorded with our standard system consisting of an Acoustic Doppler Velocimeter (ADV) for the flow measurements and a fast-responding oxygen microelectrode mounted directly onto a custom-built submersible signal 
amplifier. All Clark-type microelectrodes used (Revsbech 1989) had $90 \%$ response times $\leq 0.3 \mathrm{~s}$. The signal amplifier was developed by the Max Planck Institute for Marine Microbiology specifically for eddy correlation measurements, and the ADV, a Vector from Nortek AS, was modified to interface with this amplifier. The ADV measures and stores the three velocity components $(x-, y$-, and $z$-directions), the oxygen concentration, and the hydrostatic pressure at $64 \mathrm{~Hz}$ and, at lower resolution, the water temperature at $1 \mathrm{~Hz}$. Both the amplifier and the ADV are powered by the same external battery, and the ADV's recorder can store at least $30 \mathrm{~h}$ of data. Before deployment, the ADV was programmed to operate at $15 \mathrm{~min}$ time intervals, each consisting of a $14 \mathrm{~min}$ continuous data recording followed by a one min pause. The short pause allows the ADV also to collect data on its position above the sediment surface, which happens twice within each pause. Prior to sampling, each microelectrode was polarized for at least $12 \mathrm{~h}$ and then calibrated at the in situ temperature against two water samples of in situ salinity and known oxygen concentrations. The ADV, signal amplifier, and battery canister were mounted on a lightweight tripod with thin support legs designed for minimal disturbance of the natural flow (Berg and Huettel 2008). When the current direction is known, as was the case in this study, the frame can be configured and oriented so that any disturbances of the flow are avoided. In all deployments presented here, the eddy correlation measurements were done approximately $10 \mathrm{~cm}$ above the sediment surface. For additional calibrations, water column oxygen concentrations were also recorded multiple times with either a hand-held membrane oxygen probe (YSI) or an oxygen optode (Hach).

Chamber measurements-The in situ chambers deployed in the Wakulla River were developed by Huettel and Gust (1992b). The transparent cylindrical chambers had an inner diameter of $19 \mathrm{~cm}$ and a height of $30 \mathrm{~cm}$ and were pushed $15 \mathrm{~cm}$ into the sediment. The enclosed water was stirred by a rotating disc $(17 \mathrm{~cm}$ diameter), positioned at approximately $8 \mathrm{~cm}$ above the sediment and driven by a $12 \mathrm{~V}$ direct current motor at a preset speed. For this chamber design, a relationship has been established between the velocity of the rotating disc and the resulting static radial pressure gradient across the enclosed sediment surface (Huettel and Gust 1992b). The disc stirring speed can be adjusted to mimic typical pressure gradients at the study site, and their sizes can be inferred from measurements of bottom-current and sediment roughness. The range of roughness, including ripples, was measured with rulers prior to deploying the chambers, while the range of flow velocities was known from ADV measurements. The pressure gradient caused by the flow-topography interaction was then obtained from database values of flume measurements of pressure gradients produced for known sediment surface structures (Huettel and Gust 1992a). For the ranges of sediment roughness and current velocity in the Wakulla River, the pressure gradient ranged from 0.057 to $1.4 \mathrm{~Pa} \mathrm{~cm}-1$ corresponding to a disc stirring speed between 20 and 80 revolutions per minute (rpm). Five chambers with a preset constant stirring speed of $20,30,40,60$, and $80 \mathrm{rpm}$, respectively, were placed onto the riverbed within an area of $2 \times 3 \mathrm{~m}$. Oxygen concentrations inside the chambers were recorded every $5 \mathrm{~min}$ by oxygen optodes (Hach) mounted in the chamber lids. One additional chamber with a closed bottom was positioned on top of the riverbed and incubated bottom water only. All chambers were deployed for a period of $22 \mathrm{~h}$. Further details on the deployment and operation of in situ chambers are given by Huettel and Gust (1992b), Cook et al. (2007), and Wild et al. (2009).

Oxygen measurements within the sediments - To obtain distributions of oxygen in the sediment, point measurements were made in West Falmouth Harbor with a fiberoptic system (Ocean Optics). The optical oxygen probe had a tip $1.6 \mathrm{~mm}$ in diameter coated with a ruthenium sensing dye and was calibrated against a $100 \%$ oxygen saturation standard (relative to temperature and pressure) in ambient air and against a water sample to which sodium hyposulfite was added to produce a zero concentration. The sensor was mounted to a micromanipulator that allowed positioning of the sensor tip at known depths in the sediment with a precision of $\sim 0.2 \mathrm{~mm}$. This system was used both to measure concentration-depth profiles of oxygen and to record time series of oxygen at a fixed point in the sediment.

Light measurements - Light intensity at the sediment surface was measured during each deployment with either several submersible HOBO light loggers (Onset), a state-ofthe-art submersible spherical Quantum PAR Sensor (LICOR), or both types of sensors simultaneously. The latter allowed us, after site-specific intercalibrations, to report all light data as photosynthetically active radiation (PAR), as described by Long et al. (2012).

\section{Data treatment}

Eddy flux extractions-Fluxes were extracted from the raw eddy correlation data in a multistep process. First, oxygen concentrations measured by the microelectrode were calibrated against reference concentrations recorded concurrently with either the YSI oxygen probe or the Hach oxygen optode. Through this procedure, any small changes in microelectrode characteristics since their first determination in the lab were corrected. All data recorded at $64 \mathrm{~Hz}$ were then lumped in groups of four to produce $16 \mathrm{~Hz}$ data, which reduces noise while providing sufficient resolution to describe the entire frequency spectrum carrying the flux signal (Berg et al. 2003).

Oxygen fluxes, one for each 15 min measuring interval, were extracted from the $16 \mathrm{~Hz}$ data using the software package EddyFlux version 1.15 (P. Berg unpubl.). This software first rotates the flow velocity field for each time interval to correct for any sensor tilt. After this rotation, the transverse and vertical mean velocities equal zero. Then the eddy flux is calculated as $\overline{u_{z}^{\prime} C^{\prime}}$, where $u_{z}^{\prime}$ is the fluctuating vertical velocity around its mean, $C^{\prime}$ is the fluctuating oxygen concentration around its mean, and the bar symbolizes the averaging over the time interval (Berg 
et al. 2003). The two means, needed to isolate $u_{z}^{\prime}$ and $C^{\prime}$, were calculated as running means over the minimum number of data points determined, such that an increase in number of data points did not result in any noticeable change in flux (Berg et al. 2003; Mcginnis et al. 2008).

After calculating the eddy fluxes, a thorough data quality check was performed. This step is necessary because the fragile microelectrodes are easily affected by floating debris and organisms colliding with the sensor tip. This can produce erroneous readings that distort the flux calculation. For each time interval, the oxygen concentration and the cumulative flux were screened carefully for any abnormalities in the form of sudden jumps and changes that usually are distinguishable from natural turbulent fluctuations when the $16 \mathrm{~Hz}$ resolution data are inspected closely. At times, zoomed views covering only seconds were required to distinguish between natural and abnormal variations. Only oxygen fluxes based on natural variations were used in the further calculations. More details on flux extractions from raw eddy correlation data and the assumptions that are used in this process are given in Berg et al. (2009), Lorrai et al. (2010), and Hume et al. (2011). For selected $15 \mathrm{~min}$ time intervals, cumulative cospectra of the oxygen concentration and the vertical velocity were calculated using the software package Spectra version 1.2 (P. Berg unpubl.) to determine the eddy frequencies that carried the flux signal.

Chamber flux extractions - Oxygen fluxes were calculated from the concentration changes measured in the enclosed chamber water. For comparison, daytime and nighttime chamber fluxes were selected that covered time intervals where quality-controlled eddy fluxes existed. This was done to ensure comparisons between the two flux approaches that were as direct as possible.

Fitting averaged flux data-The eddy correlation data measured in West Falmouth Harbor were used to investigate the control of natural light and current flow on sedimentwater oxygen flux. As a first step, consecutive qualitychecked fluxes and the associated values of light and current velocity were averaged over periods of time during which close-to-steady-state conditions prevailed. It was then assumed that simple functional relationships could be established by nonlinear fitting to describe the effects of varying current flow and light on the oxygen flux. Specifically, the total oxygen flux $(J)$ was assumed to consist of two contributions: a production term $(P)$, representing light-dependent photosynthesis, and a current-dependent respiration term $(R)$. These expressions yield

$$
J=P+R
$$

where

$$
P=P_{M} \tanh \left(\frac{I}{I_{S}}\right)
$$

and

$$
R=R_{0}+R_{C} \overline{u_{x}}
$$

where $P_{M}, I_{S}, R_{0}$, and $R_{C}$ are fitting parameters that are assigned values in the same fitting process and $I$ and $\overline{u_{x}}$ are controlling variables representing light at the sediment surface and current velocity. The production term (Eq. 2) represents a standard photosynthesis-irradiance (P-I) curve, first proposed by Jassby and Platt (1976), where $P_{M}$ is the maximum oxygen production rate and $I_{S}$ is the light saturation constant. The respiration term (Eq. 3) represents respiration, including aerobic decomposition of organic carbon and oxidation of reduced products of anaerobic decay, such as $\mathrm{NH}_{4}^{+}, \mathrm{Mn}^{2+}, \mathrm{Fe}^{2+}, \mathrm{H}_{2} \mathrm{~S}, \mathrm{FeS}$, and $\mathrm{FeS}_{2}$. In the linear function assumed for respiration, $R_{0}$ can be interpreted as the diffusive oxygen uptake under low-flow conditions, and $R_{C}$ is the rate at which respiration is stimulated when the current velocity increases.

From 11 August 2009-17 August 2009, week-long continuous time series of light and current flow were compiled for West Falmouth Harbor, with a few data gaps among the measured data filled either by linear interpolation or by substituting missing data with data from other periods. When the latter approach was used to fill gaps, it was ensured that the natural periods of light and tidaldriven current flow were sustained. These time series were then used as driving variables in the fitting model (Eqs. 13 ) to generate a week-long continuous time series of oxygen flux and, from that, values of the cumulative oxygen flux and the daily net ecosystem metabolism (NEM).

Profile interpretations - To assess how important molecular diffusion was for the vertical oxygen transport in the sediment relative to advection, the concentration-depth profiles were analyzed with the profile interpretation software PROFILE (Berg et al. 1998). This software generates a statistical fit to the profile using $F$-statistics and from that calculates the oxygen flux and oxygen production-respiration rates as a function of sediment depth. PROFILE requires information on sediment porosity and, in addition, specification of animal-mediated transport if that is deemed important.

\section{Results}

Eddy correlation fluxes - Examples from West Falmouth Harbor and the Wakulla River of typical $16 \mathrm{~Hz}$ eddy correlation data and calculated fluxes, one for each $15 \mathrm{~min}$ segment of data, are shown in Figs. 1, 2. The running means used in all flux estimates for West Falmouth Harbor were defined by 2400 data points, equivalent to a timeaveraging interval of $2.5 \mathrm{~min}$. The time-averaging interval for the Wakulla River was $1 \mathrm{~min}$. The figures also show cumulative fluxes and 15 min averages of current velocity and light. The cumulative fluxes for both sites show clear trends indicating a consistent flux signal in the data.

At both sites, floating debris and organisms frequently collided with the oxygen sensor tips. Two examples from the Wakulla River are illustrated in insets in Fig. 2B. In the first case, the electrode continued to work, although the collision resulted in a slight change in electrode characteristics as reflected in the $\sim 2 \%$ increase in mean concentration. In the second case, the impact permanently 

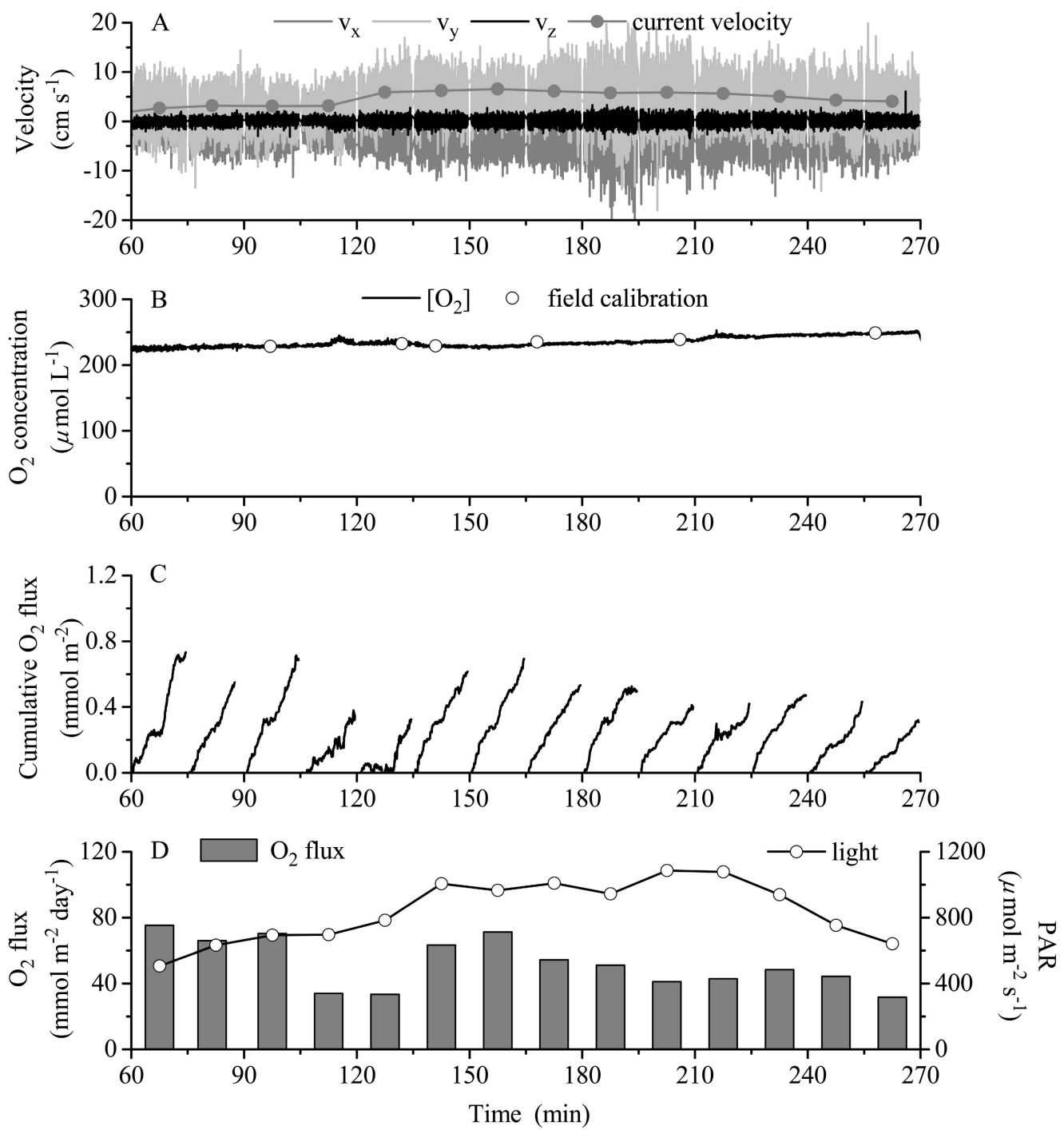

Fig. 1. Typical eddy correlation data through $3.5 \mathrm{~h}$ for West Falmouth Harbor (14:00-17:30 h, 07 August 2008). Data were recorded $10 \mathrm{~cm}$ above the sediment surface in 15 min time intervals containing 14 min continuous data recordings and a 1 min pause. (A) Three velocity components and mean current velocity. (B) Oxygen concentrations recorded with a fast-responding microelectrode and calibrated against a stable oxygen sensor. (C) Cumulative fluxes showing clear trends indicative of a strong flux signal in the data. (D) Derived fluxes and measured light (PAR) at the sediment surface, one pair for each 15 min time interval. Positive fluxes indicate a release of oxygen from the sediment.

damaged the sensor and prohibited any further flux extractions. A close inspection of the full $8.5 \mathrm{~h}$ data set (Fig. 2B) revealed that the sensor was affected by debris 11 times during this period. When collisions produced visible sudden changes in the oxygen concentration or the cumulative flux, the affected data sequence was discarded. For the two eddy correlation systems deployed side by side for $24 \mathrm{~h}$ in the Wakulla River, the fast-responding oxygen sensors were destroyed after $\sim 4$ and $\sim 10 \mathrm{~h}$. During the first $4 \mathrm{~h}$ where both systems worked, they gave comparable mean fluxes that agreed within $10 \%$ (data not shown).

During the summer in West Falmouth Harbor, abundant drifting snails (Bittium sp.) of $\sim 1 \mathrm{~mm}$ in size that frequently attached to the oxygen electrodes and caused unreliable readings represented an additional challenge (data not shown). Due to this and also to substantial amounts of floating debris at this site, only $\sim 15 \%$ of the total deployment time resulted in reliable fluxes.

During the spring of 2007 and the summers of 2007, 2008, and 2009, 10 high-quality eddy correlation data sets, such as the one shown in Fig. 1, were produced. Table 1 summarizes the representative mean values of derived fluxes and associated current velocities and light levels. Substantial variation was found in all three variables, with the oxygen flux ranging from an uptake of $-29.3 \pm$ $2.8 \mathrm{mmol} \mathrm{m}^{-2} \mathrm{~d}^{-1}(\mathrm{SE}, n=14)$ to a release of $77.5 \pm$ $13.8 \mathrm{mmol} \mathrm{m}^{-2} \mathrm{~d}^{-1}$ (SE, $\left.n=13\right)$, with current velocity from $3.3 \pm 0.3 \mathrm{~cm} \mathrm{~s}^{-1}$ (SE, $\left.n=14\right)$ to $15.5 \pm 1.1 \mathrm{~cm} \mathrm{~s}^{-1}$ (SE, $n=14$ ), and with light from 0 to $1640 \pm$ $217 \mu \mathrm{mol} \mathrm{m} \mathrm{m}^{-2} \mathrm{~s}^{-1}$ (SE, $\left.n=13\right)$. The mean values in 

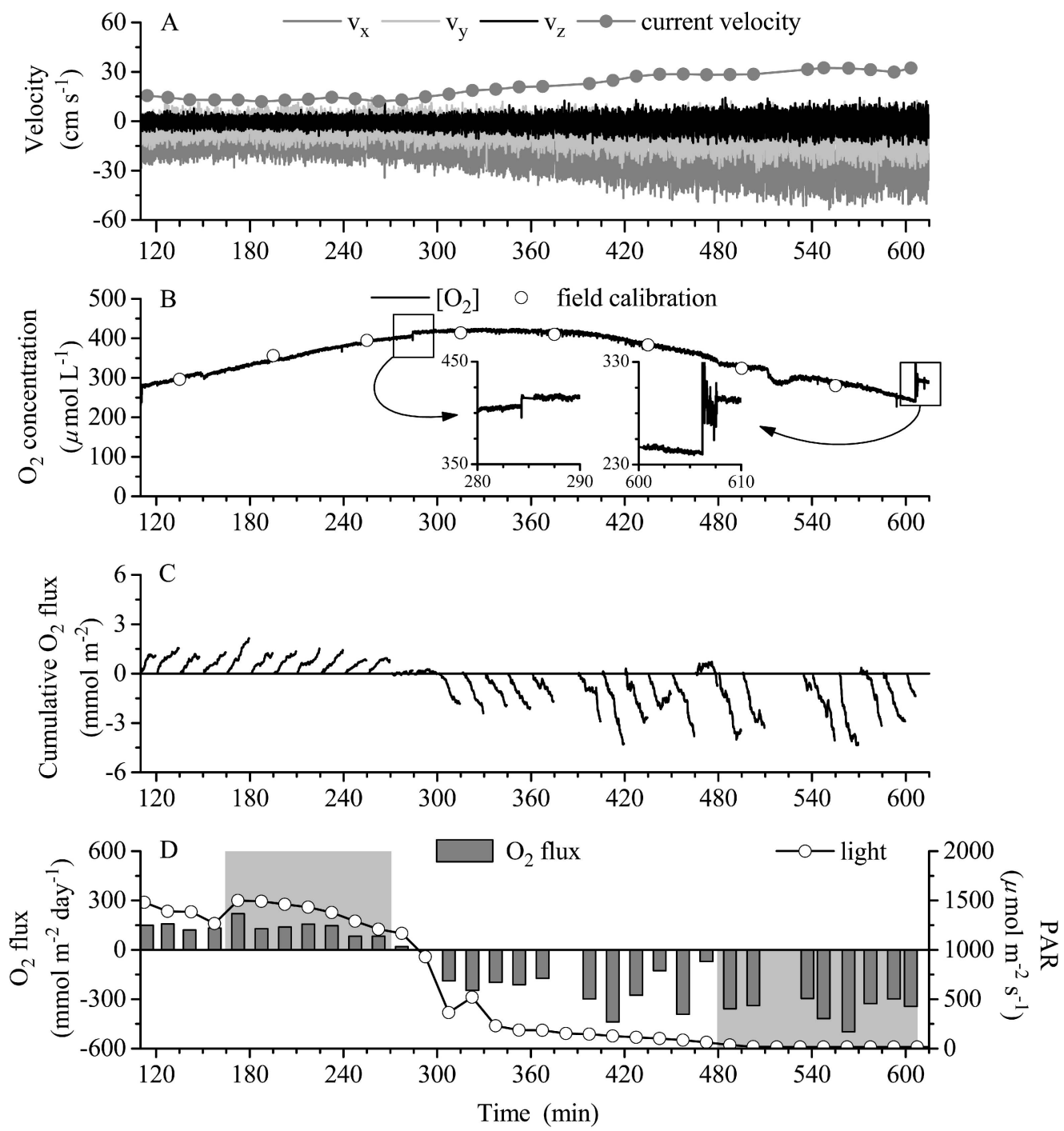

Fig. 2. Typical eddy correlation data through $8.5 \mathrm{~h}$ for Wakulla River (13:50-22:20 h, 02 May 2008). (A-D) Same as in Fig. 1. (B, insets) Examples of floating debris or organisms that collided with the oxygen microelectrode tip and affected the sensor reading. In the last example, the sensor was permanently damaged. (D) Gray-shaded areas represent periods where high-quality fluxes were also obtained from chamber deployments.

Table 1 were used as input data to the fitting model, given by Eqs. 1-3, to generate site-specific fitting parameters values for $P_{M}, I_{S}, R_{0}$, and $R_{C}$ for West Falmouth Harbor.

Typical normalized cospectra of the oxygen concentration and the vertical velocity from West Falmouth Harbor and the Wakulla River are shown in Fig. 3. The two spectra had close-to-linear increases with decreasing frequencies, starting at $\sim 1 \mathrm{~Hz}$, and revealed that the turbulent fluctuations carrying the eddy flux signal had frequencies stretching over at least two decades. These characteristics are indicative of turbulent mixing generated by quasi-steady current flow, as opposed to wave action, which would show up in the spectra as a steep climb within a narrow frequency band. These results also indicate that our oxygen electrodes with a $90 \%$ response time of $\leq 0.3 \mathrm{~s}$ were fast enough to capture all important fluctuations at both sites. The negative dip in both spectra around $1-2 \mathrm{~Hz}$, caused by a time lag between the velocity and oxygen signals (Lorrai et al. 2010), was small $(<2 \%)$, and thus a time lag correction was deemed unnecessary.

Chamber fluxes-The results from the chamber deployments in the Wakulla River are shown in Fig. 4. The oxygen concentration in all chambers reflected the daynight cycle (Fig. 4A), but with substantial variation between the individual chamber fluxes that exceeded a factor of 2 during both daytime and nighttime (129 vs. $348 \mathrm{mmol} \mathrm{m}^{-2} \mathrm{~d}^{-1}$, Fig. $4 \mathrm{~B} ;-50$ vs. $-120 \mathrm{mmol} \mathrm{m}^{-2} \mathrm{~d}^{-1}$; Fig. 4C). However, the magnitude of these individual fluxes did not correlate to the different stirring rates imposed in the chambers, which indicated that the large differences were caused by inhomogeneities in or on the permeable sediment. The significant variation in sediment permeability for this site $\left(2.3 \times 10^{-10} \pm 3.8 \times 10^{-11} \mathrm{~m}^{2}\right.$, $\mathrm{SE}, n=3$ ) supports this interpretation. The oxygen production and respiration in the control chamber were 


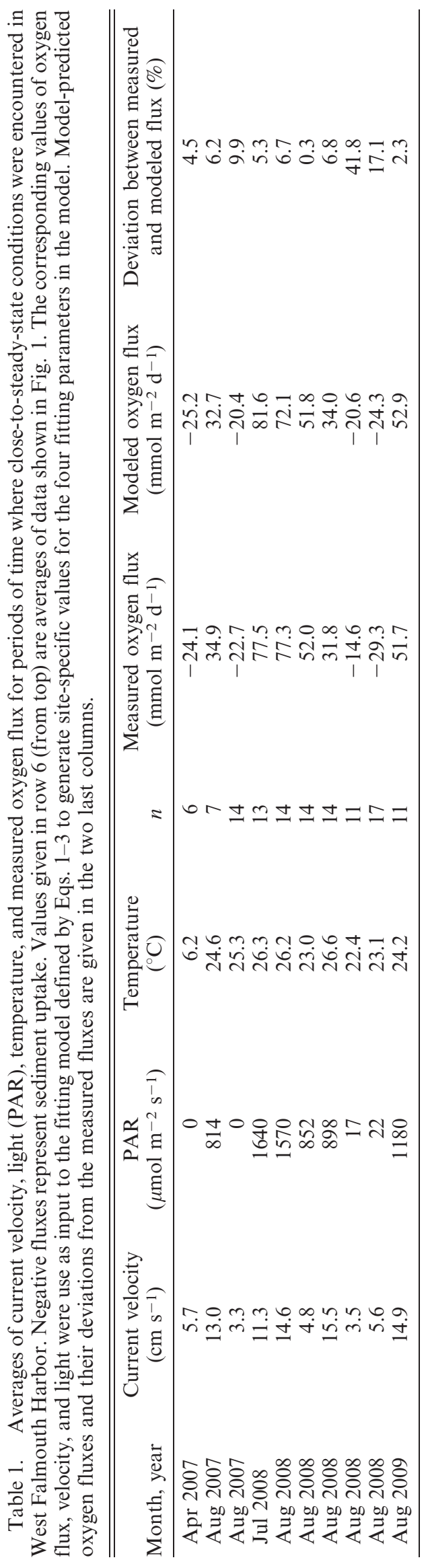

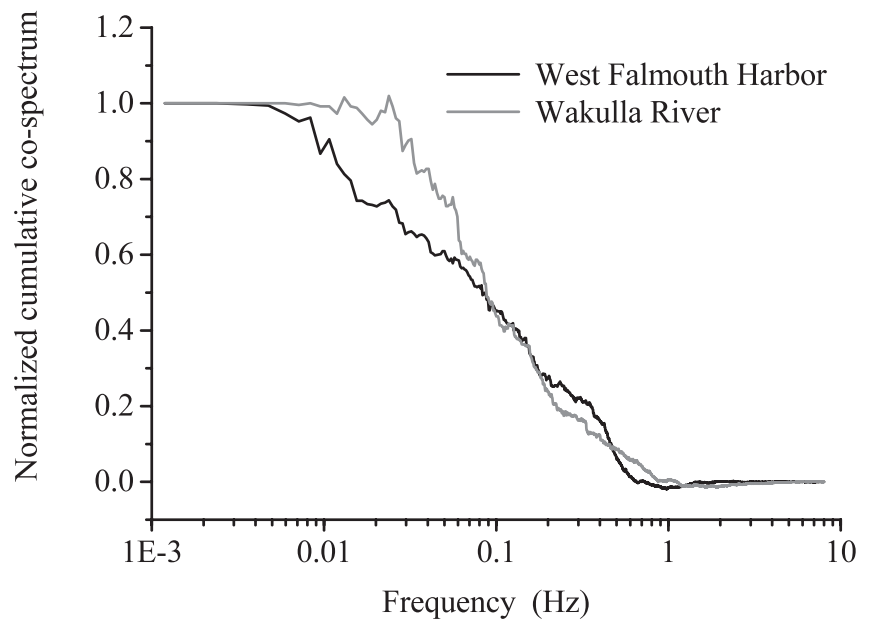

Fig. 3. Examples of normalized cumulative cospectra of the oxygen concentration and the vertical velocity. The spectra are calculated for the seventh time interval (minutes 150-165) of the West Falmouth Harbor data shown in Fig. 1 and for the fifth time interval (minutes 165-180) of the Wakulla River data shown in Fig. 2.

less than $\pm 1.0 \mathrm{mmol} \mathrm{m}^{-2} \mathrm{~d}^{-1}$, indicating that production and respiration in the water column was insignificant relative to the sediment-water exchange.

Eddy fluxes vs. chamber fluxes-The gray-shaded areas in Figs. 2D, 4A, represent the same time periods during which high-quality fluxes were obtained with both the eddy correlation technique and chambers in the Wakulla River. The daytime and nighttime mean fluxes for the two methods are compared in Fig. 5. During daytime, a slightly smaller flux (not significantly different, $p=0.07$ ) was found for the eddy correlation technique. In contrast, during nighttime, an eddy flux 4.1 times larger than the chamber flux was found. The two mean chamber fluxes shown in Fig. 5 have values of $200.0 \pm 38.9 \mathrm{mmol} \mathrm{m}^{-2} \mathrm{~d}^{-1}(\mathrm{SE}, n=5)$ and $-88.8 \pm$ $12.8 \mathrm{mmol} \mathrm{m}^{-2} \mathrm{~d}^{-1}(\mathrm{SE}, n=5)$, while the two mean eddy fluxes equal $136.6 \pm 17.7 \mathrm{mmol} \mathrm{m}^{-2} \mathrm{~d}^{-1}(\mathrm{SE}, n=7)$ and $-359.8 \pm 24.0 \mathrm{mmol} \mathrm{m}^{-2} \mathrm{~d}^{-1}(\mathrm{SE}, n=8)$. The current velocity for the two gray-shaded areas in Figs. 2D, 4A, were significantly different, with means of $13 \pm 0.3 \mathrm{~cm} \mathrm{~s}^{-1}$ (SE, $n=$ 7 ) and $31 \pm 0.6 \mathrm{~cm} \mathrm{~s}^{-1}(\mathrm{SE}, n=8)$ for daytime and nighttime, respectively, but with little variation within each time interval (Fig. 2A). The averaged daytime and nighttime water column oxygen concentrations for the same periods were 362 and $292 \mu \mathrm{mol} \mathrm{L}^{-1}$ (Fig. 2B), while the equivalent values measured inside the chambers (Fig. 4A) were $362 \pm 6 \mu \mathrm{mol} \mathrm{L}^{-1}$ (SE, $n=5)$ and $413 \pm 18 \mu \mathrm{mol} \mathrm{L}{ }^{-1}(\mathrm{SE}, n=5)$. Finally, the maximum concentration inside the chambers recorded at the end of the afternoon was $466 \pm 22 \mu \mathrm{mol} \mathrm{L}-1$ (SE, $n=5)$, which was not significantly different $(p=0.07)$ from the value of $412 \mu \mathrm{mol} \mathrm{L}-1$ measured outside the chambers.

Oxygen measurements in sediment-The oxygen profiles measured during daytime in West Falmouth Harbor shown in Fig. 6 had distinct subsurface maxima due to photosynthetic oxygen production below the sediment-water interface. Although the profiles were measured within the same 

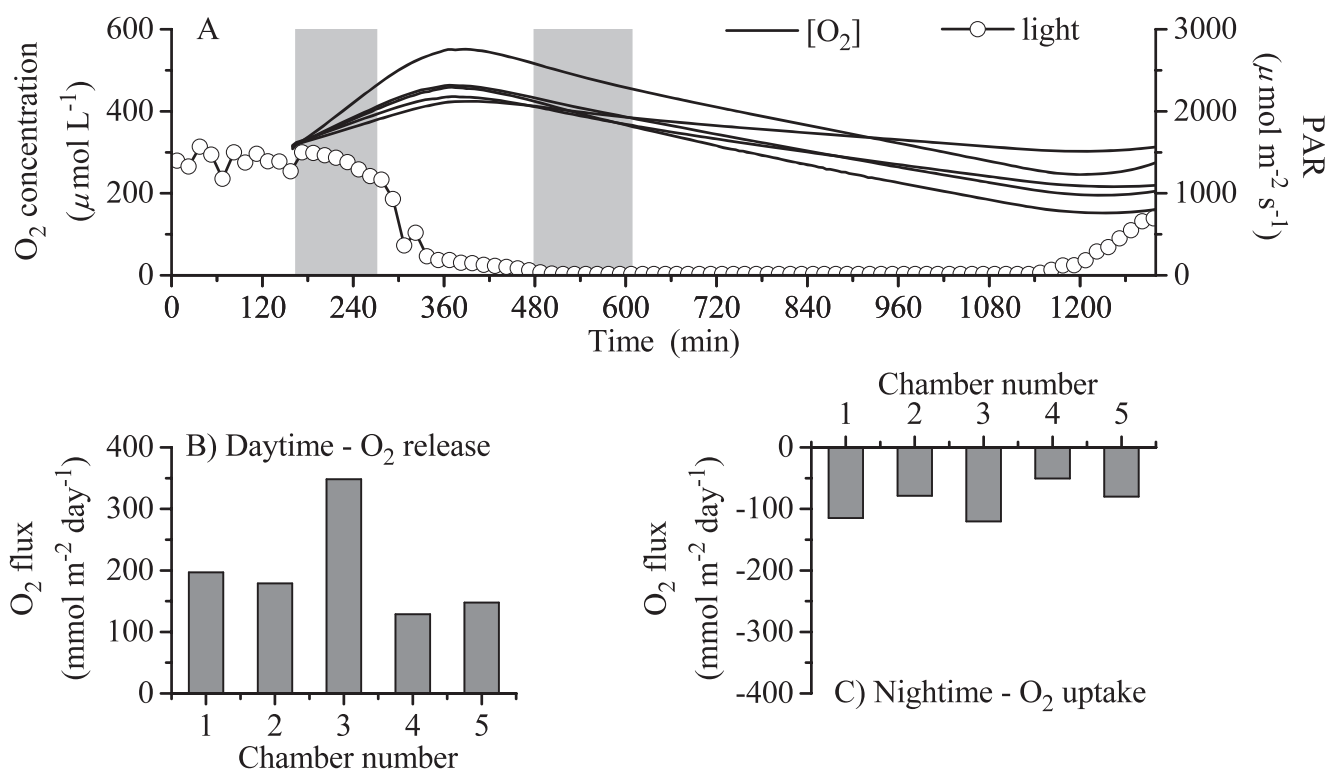

Fig. 4. Chamber data for the $22 \mathrm{~h}$ deployment in the Wakulla River. (A) Oxygen concentrations measured in five chambers and light (PAR) at the bottom. Gray-shaded areas represent periods where high-quality fluxes were also obtained from eddy correlation measurements (see Fig. 2). (B) Daytime fluxes for the five chambers. (C) Nighttime fluxes for the five chambers.
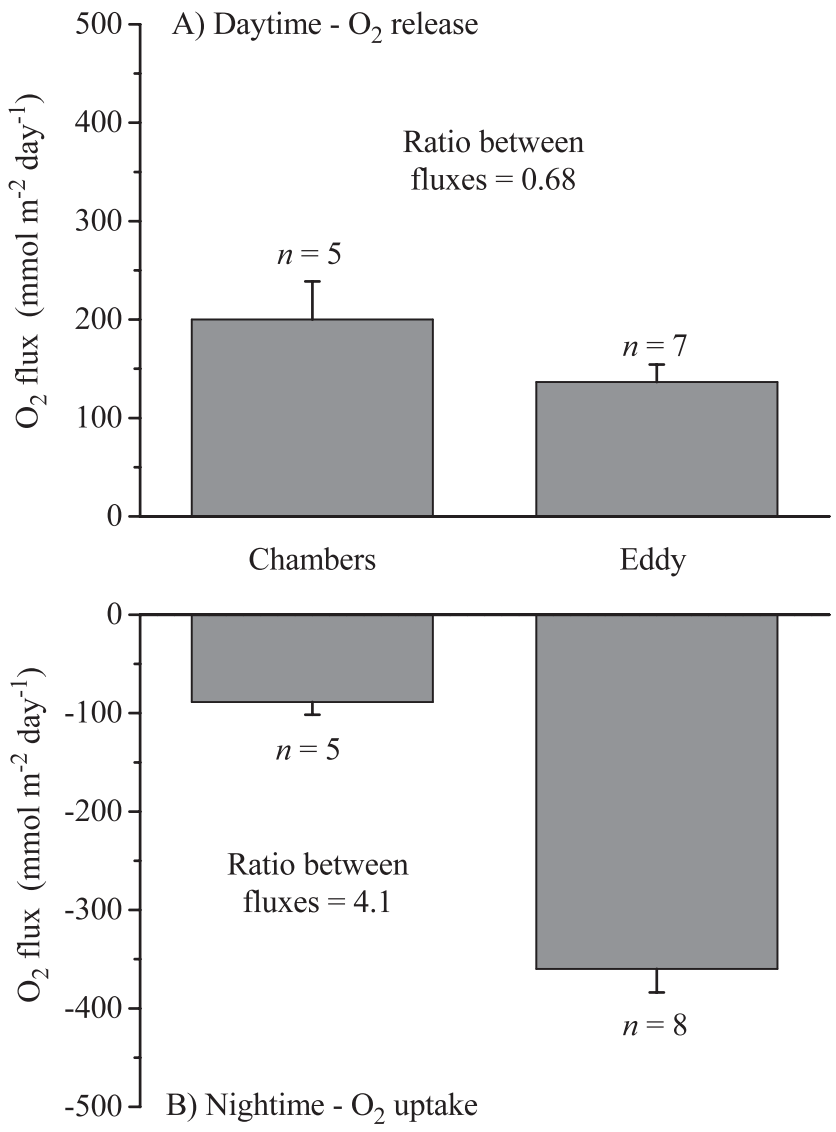

Fig. 5. Comparison of chamber and eddy fluxes measured concurrently in the Wakulla River. (A) Daytime fluxes were measured at a current velocity of $13 \mathrm{~cm} \mathrm{~s}^{-1}$. (B) Nighttime fluxes were measured at a current velocity of $31 \mathrm{~cm} \mathrm{~s}^{-1}$. A substantial difference was found between the two flux methods during nighttime. Error bars represent SE. hour and square meter, the two profiles were quite different, as reflected in the more than 2-fold difference in the penetration depths. The profile interpretations with PROFILE (Berg et al. 1998) that assumed molecular diffusion as the only active form of transport fitted the measured profiles well $\left(R^{2}=0.997\right.$ and 0.999$)$ and resulted in small sediment-water fluxes of 4.3 and $1.5 \mathrm{mmol} \mathrm{m}^{-2} \mathrm{~d}^{-1}$. In contrast, the eddy flux measured concurrently with the profiles equaled $54.2 \pm 8.7 \mathrm{mmol} \mathrm{m}^{-2} \mathrm{~d}^{-1}(\mathrm{SE}, n=3)$. The current velocity during that time was $5.7 \pm 0.4 \mathrm{~cm} \mathrm{~s}^{-1}(\mathrm{SE}$, $n=3)$.

The time series measured in West Falmouth Harbor of current velocity and oxygen concentration at a fixed point $\sim 1 \mathrm{~cm}$ below the sediment surface during incoming tide are shown in Fig. 7. The oxygen concentration showed a clear correlation to current velocity. The concentration increased from anoxic levels at smaller current flows to $\sim 65 \%$ of the water column concentration when the current increased and after that dropped to close-to anoxic levels again at lower velocities.

Controls of oxygen exchange-The fitting model (Eqs. 13 ), applied to the averaged data from West Falmouth Harbor (Table 1; Fig. 8), predicted accurately all measured oxygen fluxes from the early spring of 2007 and the summers of 2007, 2008, and $2009\left(R^{2}=0.992\right)$. This good agreement indicated that light and current flow were the major controls of benthic oxygen exchange. Averaged over all 10 fluxes, the deviation between measured and modeled fluxes equaled $10 \%$. The largest deviation of $42 \%$ was found for a relatively small oxygen uptake in August 2008 (Table 1). The site-specific values of the four fitting parameters in Eq. 2 and Eq. 3, all obtained in the same fitting process, equaled $P_{M}=149.4 \mathrm{mmol} \mathrm{m}^{-2} \mathrm{~d}^{-1}, I_{S}=$ $1499 \mu \mathrm{mol} \mathrm{m}^{-2} \mathrm{~s}^{-1}$, and $R_{0}=-15.31 \mathrm{mmol} \mathrm{m}^{-2} \mathrm{~d}^{-1}$, and $R_{C}=-1.990 \mathrm{mmol} \mathrm{s} \mathrm{m}-2 \mathrm{~d}^{-1} \mathrm{~cm}^{-1}$. The two fitting 

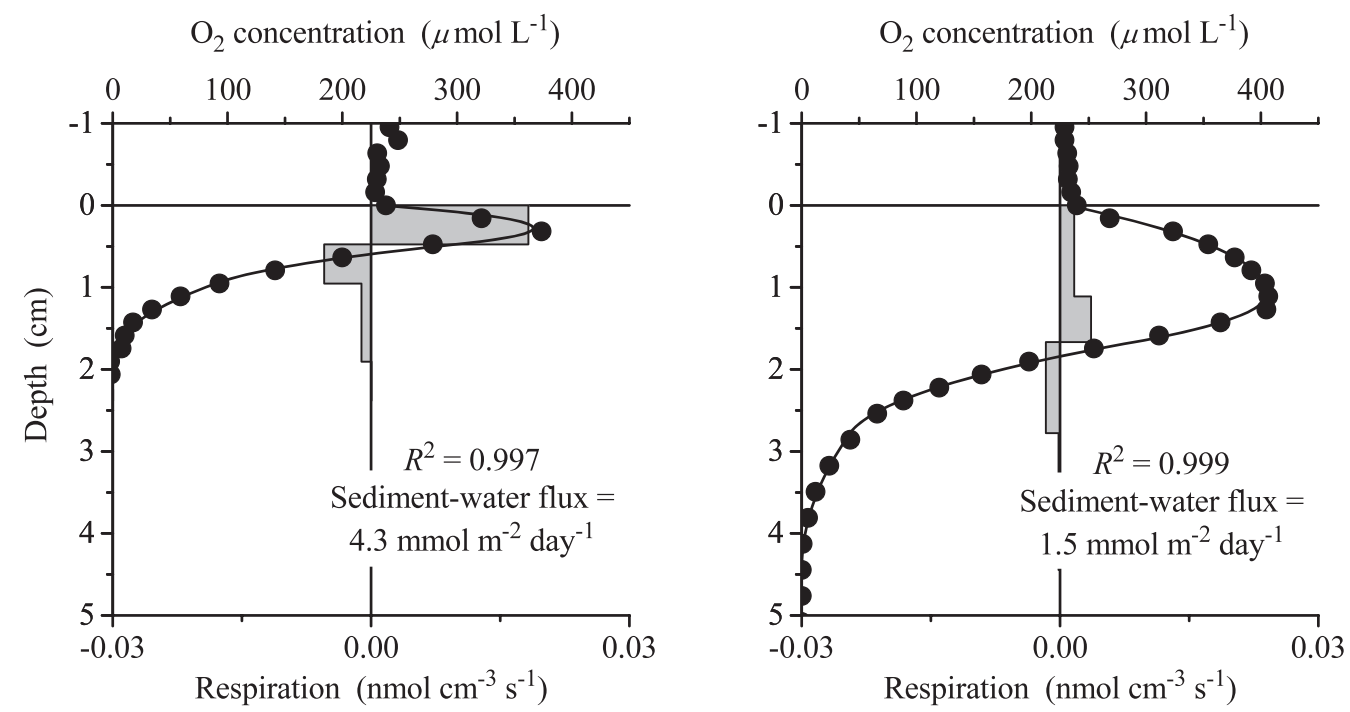

Fig. 6. Oxygen concentration-depth profiles measured in West Falmouth Harbor during daytime and zones of oxygen production and respiration calculated with the profile interpretation procedure PROFILE (Berg et al. 1998). Although the profiles were measured within the same hour and square meter, they were quite different as reflected in the oxygen penetration depths of (A) $1.7 \mathrm{~cm}$ and (B) $4.1 \mathrm{~cm}$. The calculated sediment-water fluxes due to molecular diffusion of 4.3 and $1.5 \mathrm{mmol} \mathrm{m}^{-2} \mathrm{~d}^{-1}$ were insignificant relative to the eddy flux of $54 \mathrm{mmol} \mathrm{m} \mathrm{m}^{-2} \mathrm{~d}^{-1}$ measured at the same time and at a current velocity of $5.7 \mathrm{~cm} \mathrm{~s}^{-1}$.

functions (Eqs. 2, 3) are shown in Fig. 9 along with 'pseudo-measured data' that are calculated by adding the deviations between each pair of measured and modeled fluxes (Fig. 8A) to each of the two functions. The fitting results show that only about $80 \%$ of the maximum oxygen
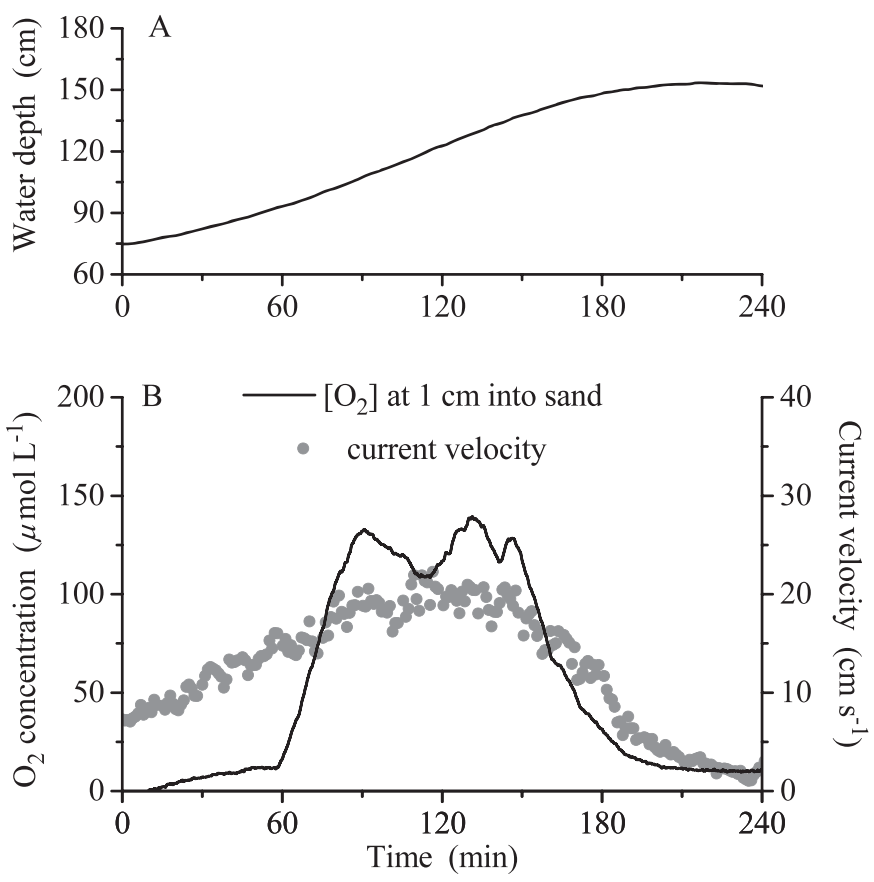

Fig. 7. Oxygen concentration at a fixed point $\sim 1 \mathrm{~cm}$ below the sediment surface measured at varying current velocities through $4 \mathrm{~h}$ in West Falmouth Harbor. (A) Water depth. (B) Current velocity and oxygen concentration. The strength of the current flow strongly affected the oxygen concentration in the sediment. production rate was reached at the highest measured light level (Fig. 9A; $1640 \mu \mathrm{mol} \mathrm{m}^{-2} \mathrm{~s}^{-1}$ ) and that respiration increased by about four times when the current velocity increased from 0 to $20 \mathrm{~cm} \mathrm{~s}^{-1}$ (Fig. 9B).

The week-long continuous time series of mostly measured values of light and current velocity compiled for West Falmouth Harbor are shown in Fig. 10 along with the oxygen flux calculated from the fitting model (Eqs. 1-3) using light and current velocity as driving variables. The cumulative flux and daily NEM rates are also shown in the figure. The oxygen flux (Fig. 10C) showed substantial dynamic changes during both day and night, with the exchange varying more than a factor of 2 from the respective nighttime and daytime means. The cumulative flux equaled zero at four times during the week (Fig. 10D), indicating a balance at these times between the timeintegrated production and respiration of oxygen in the sand. Although the NEM rates represent $24 \mathrm{~h}$ integrations of the oxygen flux, they varied considerably throughout the week, with a minimum and maximum value of -26.7 and $30.6 \mathrm{mmol} \mathrm{m}^{-2} \mathrm{~d}^{-1}$, respectively, and a mean of $-2.9 \pm 7.5 \mathrm{mmol} \mathrm{m}^{-2} \mathrm{~d}^{-1}(\mathrm{SE}, n=7)$ that was not significantly different from zero $(p=0.71)$.

\section{Discussion}

Controls of oxygen exchange-Researchers have argued that all known measuring equipment will disturb the advective flow in permeable sediments and affect measured rates (de Beer et al. 2005). However, if applied carefully and if the current direction is known as in this study, eddy correlation systems can be positioned so that such disturbances of the natural flow and light are avoided. This allows us to study oxygen fluxes and their drivers in permeable sediments in a way that has not been done before. 

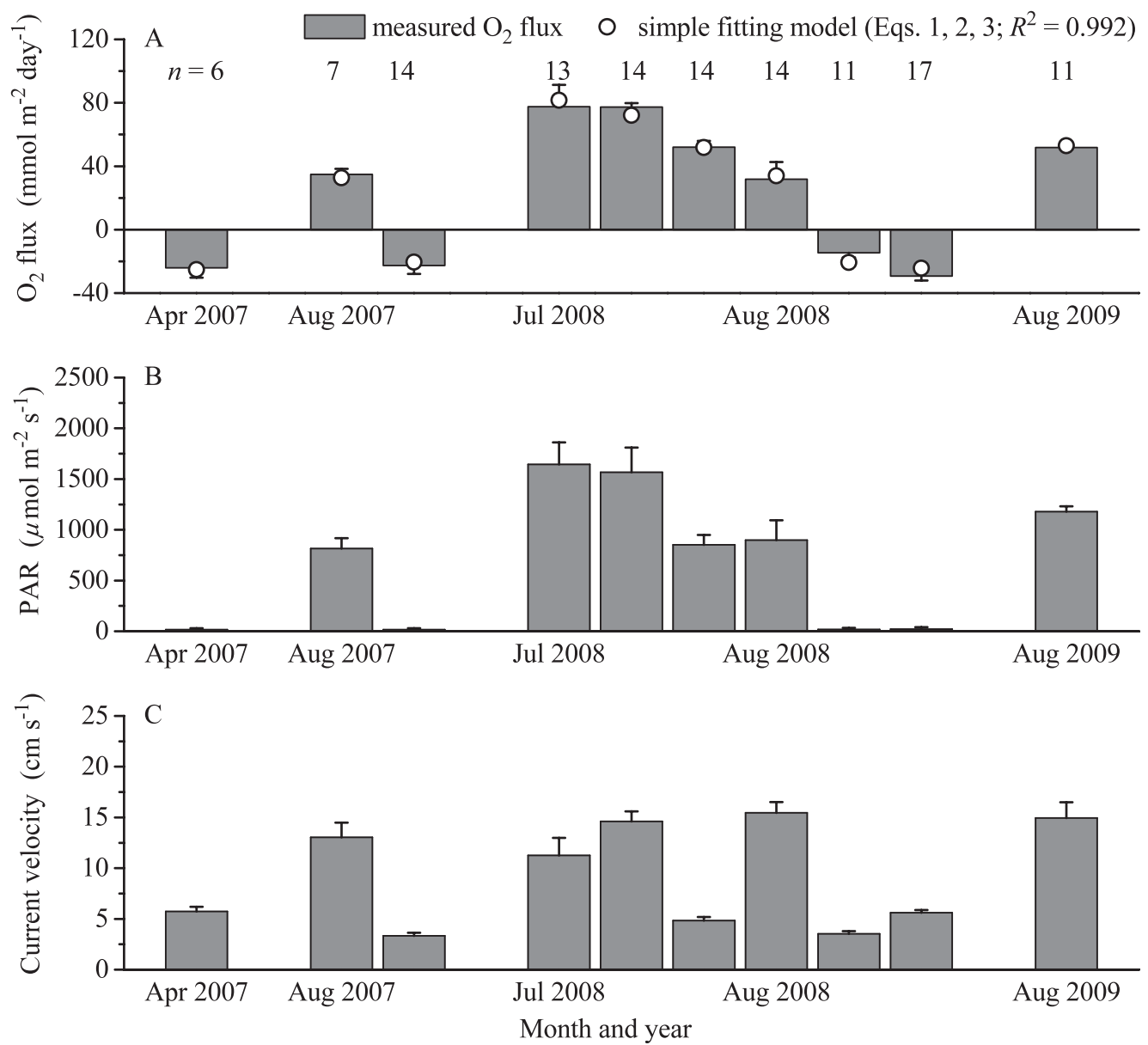

Fig. 8. Eddy fluxes, modeled fluxes, and variables controlling the oxygen exchange in West Falmouth Harbor. (A) Averages of highquality eddy flux records such as the one shown in Fig. 1 and fluxes predicted by the fitting model (Eqs. 1-3). Corresponding averages of (B) light (PAR) at the bottom and (C) current velocity. Bar 6 in each panel represents averages of data shown in Fig. 1. The fitting model gave excellent predictions of all measured eddy fluxes. Error bars represent SE.

A good example of this is the strong stimulation of oxygen uptake by current flow, equaling a factor of 4 when the current velocity increased from $\sim 0$ to $20 \mathrm{~cm} \mathrm{~s}^{-1}$ (Fig. 9B; Eq. 3), that we found in West Falmouth Harbor. Although such a relationship is intuitive and has been predicted from flushing experiments with permeable sand cores in the lab and from in situ chambers exposed to enhanced stirring (Reimers et al. 2004; de Beer et al. 2005; Cook et al. 2007), our eddy correlation data are the first of their kind that document and quantify this linkage based on direct in situ flux measurements. Even without applying the fitting model (Eqs. 1-3), this stimulation of oxygen uptake by current flow can be identified in the averages of measured values shown in Fig. 8. For example, flux 6 (Fig. 8A, from left) is $\sim 70 \%$ larger than flux 7 even though the two fluxes are associated with a similar light level (Fig. 8B) because flux 7 was measured at a $\sim 260 \%$ larger current velocity than flux 6 (Fig. 8C). The higher current stimulated oxygen respiration and resulted in the smaller net oxygen release. Our oxygen time series measured with oxygen sensors embedded $\sim 1 \mathrm{~cm}$ into the same sediment (Fig. 7) shows that this strong stimulation of oxygen respiration by current flow was linked to both a more intense and a deeper flushing of the permeable sand. These results, (Fig. 7) also indicate high sediment oxygen respiration, represented by the fast drop in oxygen concentration when oxygen supply was reduced after the current declined again. Furthermore, the flux associated with molecular diffusion found in the profile interpretations (Fig. 6) was $\sim 20$ times smaller than the eddy flux recorded at the same time, indicating that vertical oxygen transport was almost exclusively advective.

The P-I curve included in the fitting model (Fig. 9A; Eq. 2) also represents a result produced under true in situ conditions, in this case the total depth-integrated oxygen production by the benthic microalgae community. Despite the high light levels measured at the sediment surface (1640 $\mu \mathrm{mol} \mathrm{m}^{-2} \mathrm{~s}^{-1}$; Fig. $8 \mathrm{~B}$ ), only $\sim 80 \%$ of the potential maximum oxygen production was reached (Fig. 9A). This makes the maximum production rate found in the fitting process $\left(P_{M}=149.4 \mathrm{mmol} \mathrm{m}^{-2} \mathrm{~d}^{-1}\right.$; Eq. 2) somewhat uncertain, but we do note that it is in line with the maximum carbon fixation rates found in forced flushing experiments by Cook and Roy (2006) for temperate sand inhabited by microalgae. The fact that the maximum oxygen production was not reached in our measurements 

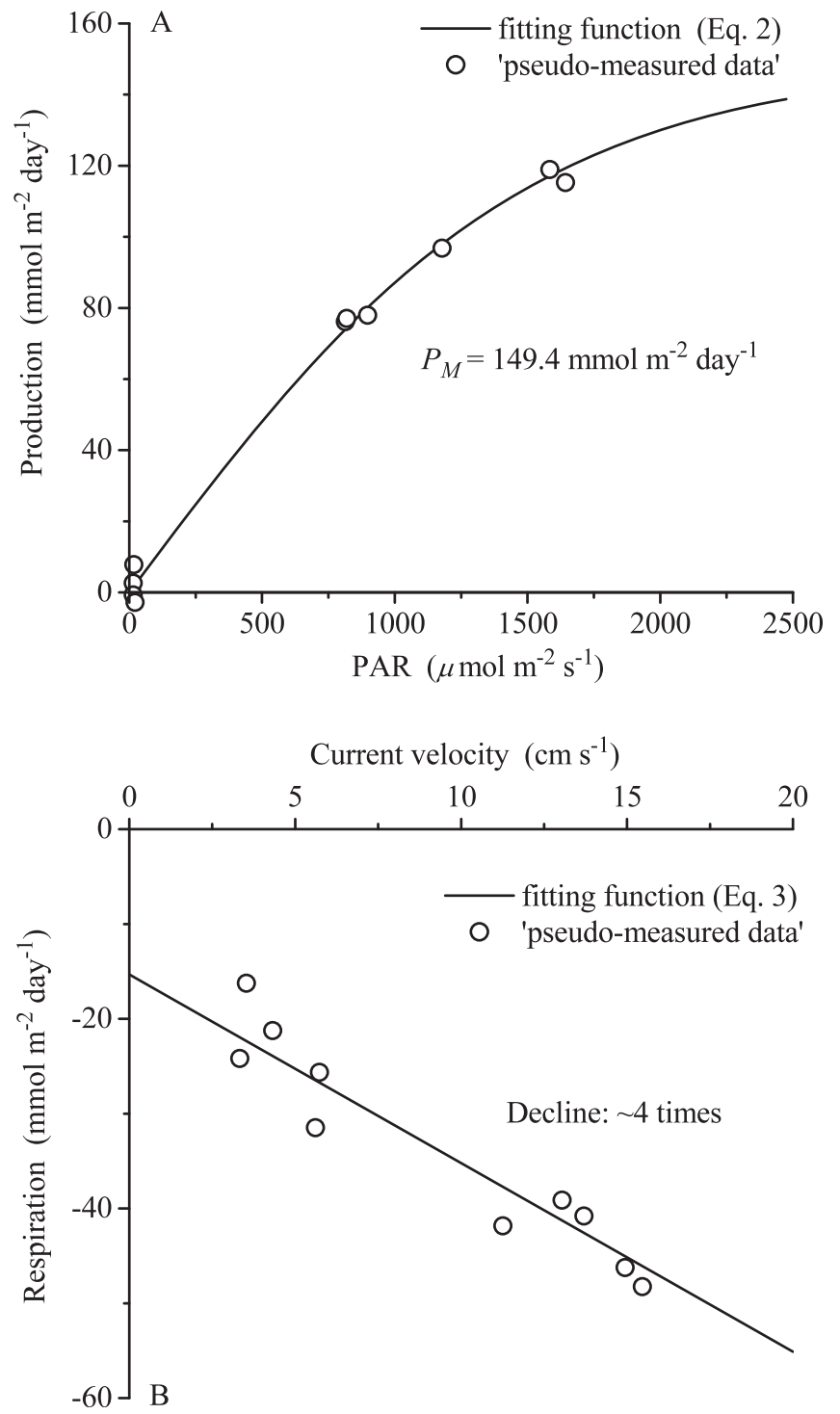

Fig. 9. Functions in the fitting model (Eqs. 1-3) representing (A) light-controlled oxygen production and (B) current flowcontrolled respiration of in West Falmouth Harbor. The 'pseudomeasured data' were obtained by adding the deviations between each pair of measured and modeled fluxes (see Fig. 8A) to each of the two functions.

can be attributed to photosynthesizing microalgae being vertically distributed in the sediment and to light attenuation with sediment depth. The subsurface maxima found in the measured oxygen concentration-depth profiles (Fig. 6) and located 0.3 and $1.1 \mathrm{~cm}$ below the sediment surface support this explanation.

The close agreement between the measured and the modeled fluxes for West Falmouth Harbor (Fig. 8A) was partly the result of applying the fitting model to averaged values of oxygen flux, light, and current velocity covering hours of data (Fig. 8; Table 1). This removes some of the faster dynamic changes and uncertainties included in the 15 min flux records, such as the one shown in Fig. 1D. The possible magnitude of such dynamic changes in flux is reflected in the concentration change and its time scale measured in the same sediment and shown in Fig. 7. As a first-order estimate, a $100 \mu \mathrm{mol} \mathrm{L}-1$ increase in oxygen concentration over $15 \mathrm{~min}$ in the upper $1 \mathrm{~cm}$ of the sediment at a porosity of 0.5 translates into an uptake of about $-50 \mathrm{mmol} \mathrm{m} \mathrm{m}^{-2} \mathrm{~d}^{-1}$, which matches the size of fluxes measured at this site. Such events, where accumulated anoxic pore water is flushed out of the sediment and replaced by oxygen-rich water, may also be accompanied by a washout of dissolved reduced compounds that react with oxygen to further amplify the interim change in flux.

The two smaller 15 min fluxes found between minutes 105 and 135 in West Falmouth Harbor (Fig. 1D) may represent such a flushing event driven by the concurrent increase in current velocity (Fig. 1A). However, it is also possible that the interim reduction in oxygen release was caused by a barely visible increase in mean oxygen concentration in the water column of $\sim 10 \mu \mathrm{mol} \mathrm{L}^{-1}$ (Fig. 1B). Because the eddy flux is measured above the sediment-water interface, here $10 \mathrm{~cm}$, such concentration changes can temporarily alter the vertical concentration gradient at the measuring point and thus the derived eddy flux. Since this interim reduction in flux was a natural phenomenon and was likely balanced by a similar increase in flux after the 105-135 min time interval, it was not removed from the flux record. A similar but more pronounced variation was found in the Wakulla River flux record (Fig. 2D) at the time interval from 390 to $480 \mathrm{~min}$, where the six fluxes varied several-fold. This variation occurred at the day-night transition with an associated initial drop in mean water column oxygen concentration (Fig. 2B). This likely resulted in bodies of water with slightly different oxygen concentrations moving through the measuring point, temporarily altering the vertical concentration gradient and thus the eddy flux. As seen in the cumulative flux (Fig. 2C), this variation was at times so pronounced that on the scale of a few minutes the eddy flux changed direction as if oxygen was released from the sediment (e.g., minutes 445 and 475).

There was no clear difference in how well the fitting model reproduced the fluxes during each of the three summers in West Falmouth Harbor (Fig. 8A; Table 1). This suggests that the sediment and site characteristics important for benthic oxygen exchange did not change noticeably from summer to summer. Because only one mean spring flux was measured (Fig. 8A), and because this was composed of only six 15 min eddy fluxes, the good model prediction found for this time should be interpreted cautiously.

Modeling of oxygen exchange-Substantial variations were found in the week-long flux record produced for West Falmouth Harbor with the fitting model (Fig. 10; Eqs. 1-3) using mostly measured values of light and current velocity as driving variables. Even when the fluxes were integrated to give daily NEM, large variations were found (Fig. 10D). The implication of this finding is that multiple 24-h periods must be integrated to produce a representative mean value for NEM due to variations in current flow (Fig. 10B) combined with the pronounced day-to-day variation in the light (Fig. 10A). For example, the first $3 \mathrm{~d}$ of the NEM record (Fig. 10D) indicated that the sediment was likely heterotrophic $\left(\mathrm{NEM}=-15.9 \pm 7.4 \mathrm{mmol} \mathrm{m}^{-2} \mathrm{~d}^{-1}, \mathrm{SE}\right.$, $p=0.08$ ), while similar data for the following 3 days 

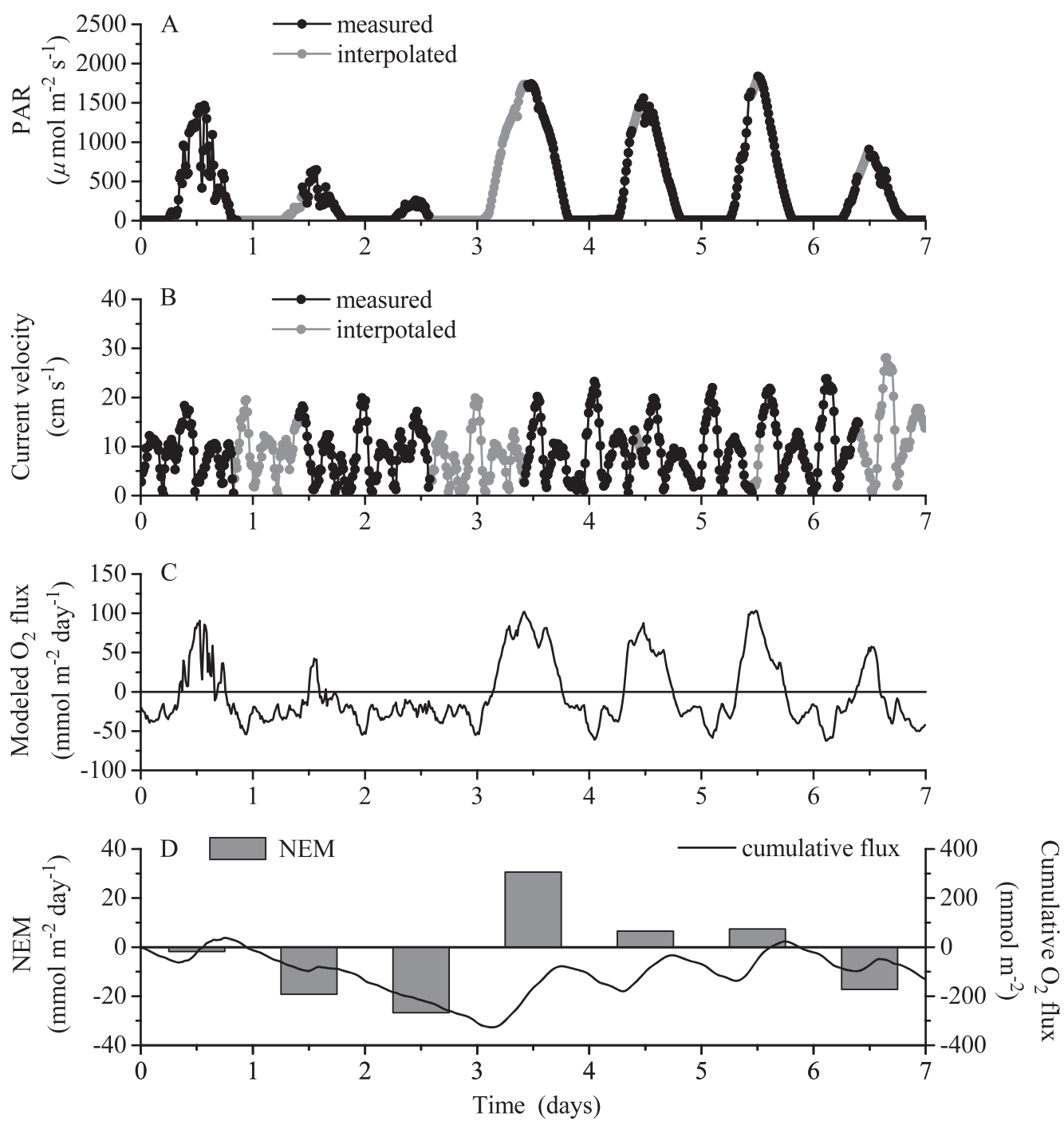

Fig. 10. Application of the fitting model (Eqs. 1-3) to a week-long record of light and current velocity compiled for West Falmouth Harbor. (A) Light (PAR) at the bottom used as a driving variable in the model. (B) Current velocity used as a driving variable in the model. (C) Oxygen flux predicted by the model. (D) Calculated daily NEM and cumulative oxygen flux through the week. Values of NEM varied substantially through the week due to variations in light and current flow. A perfect metabolic balance between oxygenproducing and oxygen-consuming processes was found four times during the week as indicated by the cumulative flux equaling zero.

suggested that the sediment was likely autotrophic (NEM = $14.9 \pm 7.9 \mathrm{mmol} \mathrm{m}^{-2} \mathrm{~d}^{-1}$, SE, $\left.p=0.10\right)$. Based on the full week of data, the sediment appeared to be in metabolic balance (NEM $=-2.9 \pm 7.5 \mathrm{mmol} \mathrm{m}^{-2} \mathrm{~d}^{-1}$, SE, $\left.p=0.71\right)$. These results suggest that if continuous flux records that include natural variations could be measured, they should be integrated over substantial periods of time - maybe several weeks - to give representative estimates of system metabolism and correct assessment of the system's trophic status. In this context, we believe that West Falmouth Harbor sediment is representative of many other shallow-water systems where oxygen exchange represents a balance between oxygen-producing and oxygen-consuming processes.

Sediment-water fluxes of oxygen exchange are usually considered a good proxy for carbon mineralization and production in benthic systems (Canfield et al. 1993; Glud 2008). However, it should be noted that adequate time integration as discussed above is crucial for this similarity or relationship to hold. As pointed out by Glud (2008), this is especially important for permeable sediments because of their dynamic fluxes. As a good example, a prompt stimulation of oxygen uptake at an increase in current flow cannot be used as a direct measure of an equivalent increase in carbon mineralization, in part because release of anoxic pore water (Fig. 7) and oxidation of stored reduced compounds will likely contribute significantly to the measured oxygen flux. It is furthermore important to realize that a higher current flow can stimulate carbon mineralization on a long-term basis only if it also leads to an increase in the input of labile solid or dissolved organic carbon to the sediment.

Eddy fluxes vs. chamber fluxes-With the prominent role that benthic oxygen fluxes play in carbon budgets for 
permeable sediments, it is important that we measure them as close to their true in situ value as possible. The accuracy of these budgets depends directly on this. The side-by-side deployments in Wakulla River of eddy correlation systems and in situ chambers (Figs. 2, 4, 5) were done as realistically as possible with instrument installment, operation, and flux extraction following protocols we have developed in earlier studies. The comparison revealed daytime chamber and eddy fluxes of similar magnitude (200.0 vs. $136.6 \mathrm{mmol} \mathrm{m}-2 \mathrm{~d}^{-1}$ at a current velocity of $13 \mathrm{~cm} \mathrm{~s}^{-1}$ ), but the equivalent nighttime values were different by a factor of $4.1\left(-88.8\right.$ vs. $-359.8 \mathrm{mmol} \mathrm{m}^{-2} \mathrm{day}^{-1}$ at a current velocity of $31 \mathrm{~cm} \mathrm{~s}^{-1}$ ). Obvious differences exist between the two flux approaches, including how well they capture or mimic the natural in situ conditions and also the size of sediment surface area for which they give the flux. At the Wakulla River site, some sparse vascular plants were observed upstream from the eddy correlation systems, and it is possible that they contributed to the flux signal contained in the eddy correlation data. However, if the significant difference between the two nighttime fluxes (Fig. 5B) was noticeably influenced by respiration of these vascular plants, a similar or even bigger discrepancy would be expected during the day, with a substantially larger daytime eddy flux than the equivalent chamber flux. Our results showed the opposite trend (Fig. 5A). Furthermore, because a much higher oxygen concentration was measured in the chambers than outside during nighttime (413 vs. $292 \mu \mathrm{mol} \mathrm{L}^{-1}$ ), we also discount that differences in oxygen levels above the sediment explain even some of the substantial discrepancy between the chamber and eddy flux at night (Fig. 5B). Thus, we attribute the difference to an insufficient generation by the chambers of the rigorous pore-water flushing and its derived oxygen uptake at the high current velocity during nighttime $\left(31 \mathrm{~cm} \mathrm{~s}^{-1}\right)$. The significant stimulation of oxygen respiration with increasing current velocity that was found in West Falmouth Harbor (Fig. 9B) supports this explanation. We finally note that the large difference agrees with one of our previously published comparisons of the two approaches, also based on nighttime fluxes (Berg and Huettel 2008), which showed a 3.8-fold difference for a marine sandy sediment with current velocities below $3 \mathrm{~cm} \mathrm{~s}^{-1}$ but with distinct wave action with maximum wave orbital velocities in the range of $\pm 10-20 \mathrm{~cm} \mathrm{~s}^{-1}$.

The relatively small difference between the daytime chamber and eddy fluxes (Fig. 5A) should be interpreted cautiously, in part because the difference is not statistically significant $(p=0.07)$ and in part because daytime fluxes are more complex, being a product of both oxygen-producing and oxygen-consuming processes. However, assuming that the chambers captured the full effect of oxygen producing processes, a possible explanation for the relatively close agreement during daytime is that the chambers, at the much lower current velocity $\left(13 \mathrm{~cm} \mathrm{~s}^{-1}\right)$, were mimicking more realistically the natural pore-water flushing and its effect on oxygen-consuming processes. In contrast, if oxygen-producing processes were underrepresented in the chambers, the underestimation of oxygen-consuming processes would be equivalently larger. Unfortunately, we do not have the data needed to investigate this in any further detail.
Biogeochemical implications-The high permeability of sand that covers most of the continental shelf (Emery 1968) and that is common in estuaries, rivers, and streams (Huettel and Webster 2000) is maintained by high-energy flow-including current flow as studied here- that winnow fine particles from the sediment surface layer (Wiberg et al. 1994). The open pore space of sand and the sediment surface topography result in a tight advective coupling between the water column and sand (Fig. 7) that facilitates a very different and much more dynamic reaction scheme for biogeochemical processes than what is typically found in muddy cohesive sediments. Specifically, the deflection of bottom currents by sediment topography, including ripples, forces water and water-bound constituents into the sand via sediment-surface depressions and draws pore water from the sand at surface elevations (Webb and Theodor 1968). This exchange both removes anoxic pore water and reduced compounds from the sediment and supplies oxygen and 'food' for mineralization processes in the form of particulate and dissolved organic matter deep into the sands (Huettel and Rusch 2000; Pilditch and Miller 2006; Huettel et al. 2007). As a result, biogeochemical processes, including aerobic respiration, are closely linked to bottomcurrent characteristics and can change dramatically with ordinary tidal oscillation (Fig. 10). This tight coupling is clearly represented in our eddy flux measurements obtained under natural field conditions and extracted with the fitting model (Fig. 9B) and documents that current flow is one of the dominant controls of benthic oxygen flux in permeable sediments.

Light superimposes a second major driver of benthic oxygen exchange for shallow-water sediments by controlling photosynthetic production by microalgae and, this was also represented in our eddy flux measurements and isolated with the fitting model (Fig. 9A). The immediate effects of light in the form of oxygen production is largely decoupled from current flow patterns, with the possible exception of current-induced turbidity. However, oxygen produced in the upper sediment layers is released to the water column mainly by advective transport (Ziebis et al. 1996), which is far more important than molecular diffusion, even at moderate current flows (Fig. 6).

The rapid advective transport in permeable sediments allows the complex processes of oxygen production and respiration to be mimicked by our simple fitting model to reproduce daytime and nighttime oxygen fluxes equally well (Fig. 8A). Such simple modeling approaches may have significant merit in the future, after further parameterizations and validations, as powerful tools for carbon cycling estimates covering different size scales.

In this study, we have focused on sediment-water fluxes of oxygen in permeable sediments, major controls of these fluxes, and how well they can be measured with two stateof-the-art flux methods. Permeable sediments are ubiquitous in aquatic systems, and their exchange of oxygen with the water column is crucial as a proxy for carbon cycling rates on local and global scales. Our results on controls of benthic oxygen fluxes (Fig. 9), their dynamic nature (Fig. 10), and how we can measure them (Fig. 5) emphasize that we still have limited knowledge of the processes that 
control these benthic fluxes and that more work is necessary. We have limited this study to current-driven flows and thus omitted the complex effects of wave action. These should be included in future studies.

\section{Acknowledgments}

We thank two anonymous reviewers and Associate Editor Bo Thamdrup for helpful and constructive comments on the manuscript. Support for this study was provided by the following National Science Foundation grants: OCE-0420575, OCE0536431, and OCE-1061364.

\section{References}

Aufdenkampe, A. K., And others. 2011. Riverine coupling of biogeochemical cycles between land, oceans, and atmosphere. Front. Ecol. Environ. 9: 53-60, doi:10.1890/100014

Bear, J. 1972. Dynamics of fluids in porous media. American Elsevier.

Berg, P., R. N. Glud, A. Hume, H. Stahl, K. Oguri, V. Meyer, and H. Kitazato. 2009. Eddy correlation measurements of oxygen uptake in deep ocean sediments. Limnol. Oceanogr.: Methods 7: 576-584, doi:10.4319/lom.2009.7.576

— AND M. HuETTEL. 2008. Monitoring the seafloor using the noninvasive eddy correlation technique: Integrated benthic exchange dynamics. Oceanography 21: 164-167, doi:10.5670/ oceanog.2008.13

- , N. Risgaard-Petersen, and S. Rysgaard. 1998. Interpretation of measured concentration profiles in sediment pore water. Limnol. Oceanogr. 43: 1500-1510, doi:10.4319/lo. 1998.43.7.1500

- H. Roy, F. Janssen, V. Meyer, B. B. Jorgensen, M. Huettel, AND D. DE BEER. 2003. Oxygen uptake by aquatic sediments measured with a novel non-invasive eddy-correlation technique. Mar. Ecol. Prog. Ser. 261: 75-83, doi:10.3354/meps261075

, - AND P. L. WiberG. 2007. Eddy correlation flux measurements: The sediment surface area that contributes to the flux. Limnol. Oceanogr. 52: 1672-1684, doi:10.4319/lo.2007. 52.4.1672

CANField, D. E., AND OTHERs. 1993. Pathways of organic carbon oxidation in three continental margin sediments. Mar. Geol. 113: $27-40$, doi:10.1016/0025-3227(93)90147-N

Cole, J. J., AND OTHERs. 2007. Plumbing the global carbon cycle: Integrating inland waters into the terrestrial carbon budget. Ecosystems 10: 171-184, doi:10.1007/s10021-006-9013-8

Cook, P. L. M., AND H. Roy. 2006. Advective relief of $\mathrm{CO}_{2}$ limitation in microphytobenthos in highly productive sandy sediments. Limnol. Oceanogr. 51: 1594-1601, doi:10.4319/lo.2006.51.4.1594

- M. F. Wenzhofer, R. N. Glud, F. Janssen, and M. Huettel. 2007. Benthic solute exchange and carbon mineralization in two shallow subtidal sandy sediments: Effect of advective pore-water exchange. Limnol. Oceanogr. 52: 1943-1963, doi:10.4319/1o.2007.52.5.1943

De Beer, D., AND others. 2005. Transport and mineralization rates in North Sea sandy intertidal sediments, Sylt-Romo Basin, Wadden Sea. Limnol. Oceanogr. 50: 113-127, doi:10.4319/1o.2005.50.1.0113

EMERY, K. O. 1968. Relict sediments on continental shelves of the world. Am. Assoc. Petroleum Geologists 52: 445-464.

Fenchel, T., AND R. N. Glud. 2000. Benthic primary production and $\mathrm{O}_{2}-\mathrm{CO}_{2}$ dynamics in a shallow-water sediment: Spatial and temporal heterogeneity. Ophelia 53: 159-171.

Foster-Smith, R. L. 1978. An analysis of water flow in tube living animals. J. Exp. Mar. Biol. Ecol. 34: 73-95, doi:10.1016/0022-0981 (78)90058-8
Glud, R. N. 2008. Oxygen dynamics of marine sediments. Mar. Biol. Res. 4: 243-289, doi:10.1080/17451000801888726

Huettel, M., P. Cook, F. Janssen, G. Lavik, and J. J. Middelburg. 2007. Transport and degradation of a dinoflagellate bloom in permeable sublittoral sediment. Mar. Ecol. Progr. Ser. 340: 139-153, doi:10.3354/meps340139

— AND G. Gust. 1992a. Impact of bioroughness on interfacial solute exchange in permeable sediments. Mar. Ecol. Progr. Ser. 89: 253-267, doi:10.3354/meps089253

, AND - 1992b. Solute release mechanisms from confined sediment cores in stirred benthic chambers and flume flows. Mar. Ecol. Progr. Ser. 82: 187-197, doi:10.3354/ meps082187

- AND A. RusCh. 2000. Transport and degradation of phytoplankton in permeable sediment. Limnol. Oceanogr. 45: 534-549, doi:10.4319/lo.2000.45.3.0534

—, AND I. T. Webster. 2000. Porewater flow in permeable sediments, p. 144-179. In B. P. Boudreau and B. B. Jørgensen [eds.], Benthic boundary layer: Transport processes and biochemistry. Oxford University Press.

- W. ZiebIS, AND S. Forster. 1996. Flow-induced uptake of particulate matter in permeable sediments. Limnol. Oceanogr. 41: 309-322, doi:10.4319/1o.1996.41.2.0309

Hume, A. C., P. Berg, and K. J. Mcglathery. 2011. Dissolved oxygen fluxes and ecosystem metabolism in an eelgrass (Zostera marina) meadow measured with the eddy correlation technique. Limnol. Oceanogr. 56: 86-96, doi:10.4319/lo. 2011.56.1.0086

Jassby, A. D., And T. Platt. 1976. Mathematical formulation of relationship between photosynthesis and light for phytoplankton. Limnol. Oceanogr. 21: 540-547, doi:10.4319/lo. 1976.21.4.0540

Klute, A., And C. Dirksen. 1986. Hydraulic conductivity and diffusivity: Laboratory methods, p. 687-734. In A. Klute [ed.], Methods of soil analysis - part 1-physical and mineralogical methods. American Society of Agronomy.

Long, M. H., J. E. Rheuban, P. Berg, and J. C. Zieman. 2012. A comparison and correction of light intensity loggers to photosynthetically active radiation sensors. Limnol. Oceanogr.: Methods 10: 416-424, doi:10.4319/lom.2012.10.416

Lorrai, C., D. F. Mcginnis, P. Berg, A. Brand, and A. Wuest. 2010. Application of oxygen eddy correlation in aquatic systems. J. Atmos. Oceanic Technol. 27: 1533-1546, doi:10. 1175/2010JTECHO723.1

Mcginnis, D. F., P. Berg, A. Brand, C. Lorrai, T. J. Edmonds, AND A. Wuest. 2008. Measurements of eddy correlation oxygen fluxes in shallow freshwaters: Towards routine applications and analysis. Geophys. Res. Lett. 35: 1-5, doi:10.1029/2007GL032747

Middelburg, J. J., C. M. Duarte, and J. P. Gattuso. 2005. Respiration in coastal benthic communities, p. 206-225. In P. A. Del Giorgio and P. J. L. B. Williams [eds.], Respiration in aquatic ecosystems. Oxford University Press.

— and K. Soetaert. 2004. The role of sediments in shelf ecosystem dynamics. Geochim. Cosmochim. Acta 68: 353-373.

Pilditch, C. A., AND D. C. Miller. 2006. Phytoplankton deposition to permeable sediments under oscillatory flow: Effects of ripple geometry and resuspension. Cont. Shelf Res. 26: $1806-1825$, doi:10.1016/j.csr.2006.06.002

Precht, E., And M. Huettel. 2003. Advective pore-water exchange driven by surface gravity waves and its ecological implications Limnol. Oceanogr. 48: 1674-1684, doi:10.4319/lo.2003.48.4.1674

Reimers, C. E., AND OTHERS. 2004. In situ measurements of advective solute transport in permeable shelf sands. Cont. Shelf Res. 24: 183-201, doi:10.1016/j.csr.2003.10.005 
Revsbech, N. P. 1989. An oxygen microsensor with a guard cathode. Limnol. Oceanogr. 34: 474-478, doi:10.4319/ 10.1989.34.2.0474

Riedl, R. J., N. Huang, and R. Machan. 1972. The subtidal pump: A mechanism of interstitial water exchange by wave action. Mar. Biol. 13: 210-221, doi:10.1007/BF00391379

Swaney, D. P., D. Scavia, R. W. Howarth, and R. M. Marino. 2008. Estuarine classification and response to nitrogen loading: Insights from simple ecological models. Estuar. Coast. Shelf Sci. 77: 253-263, doi:10.1016/j.ecss.2007.09.013

TengBerg, A., AND OTHERs. 2005. Intercalibration of benthic flux chambers II. Hydrodynamic characterization and flux comparisons of 14 different designs. Mar. Chem. 94: 147-173, doi:10.1016/j.marchem.2004.07.014

Thibodeaux, L. J., and J. D. Boyle. 1987. Bedform-generated convective transport in bottom sediment. Nature 325: 341-343, doi:10.1038/325341a0

Thouzeau, G., AND others. 2007. Spatial and temporal variability of benthic biogeochemical fluxes associated with macrophytic and macrofaunal distributions in the Thau lagoon (France). Estuar. Coast. Shelf Sci. 72: 432-446, doi:10.1016/j.ecss. 2006.11.028

WebB, J. E., And J. Theodor. 1968. Irrigation of submerged marine sands through wave action. Nature 220: 682-685, doi: $10.1038 / 220682 \mathrm{a} 0$
WenZHOFER, F., AND R. N. GLud. 2004. Small-scale spatial and temporal variability in coastal benthic $\mathrm{O}_{2}$ dynamics: Effects of fauna activity. Limnol. Oceanogr. 49: 1471-1481, doi:10.4319/lo.2004.49.5.1471

Wiberg, P. L., D. E. Drake, and D. A. Cacchione. 1994. Sediment resuspension and bed armoring during high bottom stress events on the northern California Inner ContinentalShelf-measurements and predictions. Cont. Shelf Res. 14: 1191-1219, doi:10.1016/0278-4343(94)90034-5

Wild, C., M. S. Naumann, A. Haas, U. Struck, F. W. Mayer, M. Y. Rasheed, And M. Huettel. 2009. Coral sand $\mathrm{O}_{2}$ uptake and pelagic-benthic coupling in a subtropical fringing reef, Aqaba, Red Sea. Aquat. Biol. 6: 133-142, doi:10.3354/ab00181 , M. Rasheed, U. Werner, U. Franke, R. Johnstone, And M. Huettel. 2004. Degradation and mineralization of coral mucus in reef environments. Mar. Ecol. Prog. Ser. 267: 159-171, doi:10.3354/meps267159

Ziebis, W., M. Huettel, And S. Forster. 1996. Impact of biogenic sediment topography on oxygen fluxes in permeable seabeds. Mar. Ecol. Prog. Ser. 140: 227-237, doi:10.3354/meps140227

Associate editor: Bo Thamdrup

Received: 10 September 2012 Accepted: 20 February 2013 Amended: 14 March 2013 